\title{
Magnetic resonance imaging in schizophrenia: Luxury or necessity? (Review)
}

\author{
FLORIS PETRU ILIUTA ${ }^{1,2^{*}}$, MIHNEA COSTIN MANEA ${ }^{1,2^{*}}$, MAGDALENA BUDISTEANU $^{1,3,4^{*}}$, \\ ADELA MAGDALENA CIOBANU ${ }^{5,6}$ and MIRELA MANEA ${ }^{1,2}$
}

\author{
${ }^{1}$ Psychiatry Research Laboratory, 'Prof. Dr. Alexandru Obregia' Clinical Hospital of Psychiatry, 041914 Bucharest; \\ ${ }^{2}$ Department of Psychiatry and Psychology, Faculty of Dental Medicine, 'Carol Davila' University of Medicine and Pharmacy, \\ 010221 Bucharest; ${ }^{3}$ Laboratory of Medical Genetics, 'Victor Babes' National Institute of Pathology, 050096 Bucharest; \\ ${ }^{4}$ Medical Genetics Department, Faculty of Medicine, 'Titu Maiorescu' University, 031593 Bucharest; \\ ${ }^{5}$ Department of Neuroscience, Discipline of Psychiatry, Faculty of General Medicine, 'Carol Davila' University of \\ Medicine and Pharmacy, 050474 Bucharest; ${ }^{6}$ Department of Psychiatry, 'Prof. Dr. Alexandru Obregia' \\ Clinical Hospital of Psychiatry, 041914 Bucharest, Romania
}

Received March 17, 2021; Accepted April 16, 2021

DOI: 10.3892/etm.2021.10197

\begin{abstract}
Schizophrenia, one of the most common psychiatric disorders, with a worldwide annual incidence rate of approximately $0.3-0.7 \%$, known to affect the population below 25 years of age, is persistent throughout lifetime and includes people from all layers of society. With recent technological progress that allows better imaging techniques, such as the ones provided by computed tomography and particularly magnetic resonance imaging (MRI), research on schizophrenia imaging has grown considerably. The purpose of this review is to establish the importance of using imaging techniques in the early detection of brain abnormalities in patients diagnosed with schizophrenia. We reviewed all articles which reported on MRI imaging in schizophrenia. In order to do this, we used the PubMed database, using as search words 'MRI' and 'schizophrenia'. MRI studies of first episode patients and chronic patients, suggest reduction of the whole brain volume. Enlargement of lateral ventricles was described as positive in 15 studies out of 19 and was similar to findings in chronic patients. Moreover, for the first episode patients, all data collected point to important changes in medial temporal lobe structures, diminished hippocampal volume, the whole frontal lobe, asymmetry in prefrontal cortex, diminished volume in
\end{abstract}

Correspondence to: Dr Floris Petru Iliuta, Psychiatry Research Laboratory, 'Prof. Dr. Alexandru Obregia' Clinical Hospital of Psychiatry, 10-12 Berceni Street, 041914 Bucharest, Romania

E-mail: florisiliuta@gmail.com

${ }^{*}$ Contributed equally

Key words: schizophrenia, neuroleptic, magnetic resonance imaging, biomarkers, structural abnormalities, gray matter, white matter, diagnosis cingulate, corpus callosum, and cavum septum pellucidum reported abnormalities. MRI is recommended as an important tool in the follow-up process of patients with schizophrenia. Yet, it is still under debate whether the abnormalities described in this condition are able to be used as diagnostic biomarkers.

\section{Contents}

1. Introduction

2. Scope of the review

3. Literature search methods

4. Results

5. First episode patient data

6. Chronic patient data

7. Conclusions

\section{Introduction}

Schizophrenia, one of the most common psychiatric disorders, with a worldwide annual incidence rate of approximately $0.3-0.7 \%$, known to affect the population below 25 years of age, is persistent throughout lifetime and includes people from all layers of society (1). The main signs and symptoms may differ among patients as well as the debut period and can include perceptual abnormalities, delusions, deterioration of cognitive function and emotional impairment. It affects both patients and their families, manifesting in poor care and social exclusion because of the widespread ignorance about the disorder (2). Although schizophrenia has been studied for more than a century, the neuropathology of schizophrenia is still unknown, with no single set of causes that can be pinned down as an underlying mechanism for this condition (2-5). Najjar and Pearlman described, in a review of 15 studies that involved 792 patients, that schizophrenia is strongly related with white matter abnormalities and it could lead to structural 
and functional dysconnectivity, even in an early development of psychosis (6).

With recent technological progress that allows better imaging techniques, such as the ones provided by computed tomography (CT) and particularly magnetic resonance imaging (MRI), research on schizophrenia imaging has grown considerably. Multiple neuroimaging studies have identified substantial evidence of structural and functional brain alterations in schizophrenia. There is no specific region in which these alterations occur, but they are frequently found in the association cortex and subcortical (limbic, striatal) brain regions. These findings still do not have diagnostic value (7-9).

In the 19th and 20th century, there were numerous attempts to identify brain abnormalities that led to discouraging results because of the lack of technology. Although the benefits of using CT to discover brain abnormalities in vivo were important, using the newer technique of MRI, allowed researchers to better analyze different regions of the brain due to an improved picture of the gray matter (10).

\section{Scope of the review}

The main method of diagnosing schizophrenia is based on clinical diagnostic criteria, psychiatric history and mental examination of the patient, with imaging techniques being used for differential diagnosis with other disorders that could cause psychosis. The purpose of this review was to establish the importance of using imaging techniques in the early detection of brain abnormalities in patients diagnosed with schizophrenia.

\section{Literature search methods}

We reviewed all articles which reported on MRI imaging in schizophrenia. In order to do this, we used PubMed database, using as search words 'MRI' and 'schizophrenia'. Only articles indexed in PubMed, written in English and published between 1988 to 2020 were reviewed for this study.

A total of 197 article were reviewed. From these we selected 84 articles which offered information about significant brain structures mainly linked with schizophrenia: Lateral ventricles, third ventricle, fourth ventricle, temporal lobe, frontal lobe, parietal lobe, occipital lobe, cerebellum, basal ganglia structures, thalamus, corpus callosum and septum pellucidum.

\section{Results}

Although large individual variations in brain size in the general population such as gender, age, economic and social status, perinatal factors and potential nutritional deficits are reported, there are no statistically eloquent differences in MRI studies between patients diagnosed with schizophrenia and normal controls (10).

In the review conducted by Shenton et al concerning 55 MRI studies in patients with schizophrenia, 44 reported structural modifications such as enlarged lateral ventricles (10). While lateral ventricle enlargement was not always identified in some studies, enlargement of the temporal horn portion, which is commonly found on the left sided ventricle, has been mentioned (11-20).
In 33 MRI studies of the third ventricle, 24 (73\%) describe an enlargement of this area, and $9(27 \%)$ report negative findings $(10,21-23)$.

The fourth ventricle was investigated in 5 MRI studies, and only one of them reported positive findings, representing 20\%; the remaining 4 studies were negative $(10,24,25)$.

Of $51 \mathrm{MRI}$ studies evaluating the volume of temporal lobe, $31(61 \%)$ reported smaller temporal lobe volume, while $20(39 \%)$ reported negative findings (10,26-29).

MRI findings of frontal lobe abnormalities in schizophrenia are vague. From 50 MRI studies, 30 (60\%) reported volumetric reduction, while $20(40 \%)$ reported negative findings (10,30-33).

An important brain region involved in processes that are altered in schizophrenia, such as attention (34), spatial working memory (35) and language (36) is the parietal lobe. In 15 studies regarding the MRI of the parietal lobe, only $9(60 \%)$ describe abnormalities in this region $(7,10,37,38)$.

Four of the studies that describe the occipital lobe, representing $44 \%$, showed a reduction in the volume of patients diagnosed with schizophrenia $(8,9,39,40)$.

Four $(31 \%)$ out of 13 MRI studies of the cerebellum in schizophrenia, reported positive findings, while $9(69 \%)$ reported negative findings $(41,42)$. Nopoulos and coworkers $(43)$ reported negative findings, but they did report a reduction in volume in the anterior lobe of the vermis and Rossi and coworkers (44) showed a decrease in vermal-to-brain ratio in male patients with schizophrenia compared to female patients with schizophrenia.

From 25 studies involving the basal ganglia structures, 17 of them, representing 68\%, described increased volume (45-47) and 8 reporting negative results $(48,49)$. Recent studies describe that the enlargement of the basal ganglia is rather caused by neuroleptic medication $(10,47)$.

The thalamus, although an important relay station in the brain, which is involved in modulating the input from various levels such as the cortical areas, limbic system and reticular activating system, has been little scanned, mainly because this area fades from gray matter to white matter. From 12 MRI studies, 5 (42\%) describe a reduction in the volume and $7(58 \%)$ reported no discrepancy between the control group and the patients with schizophrenia (50-53).

Corpus callosum, a brain structure composed of white matter, has been reviewed in 27 MRI studies, 17 (63\%) of them reporting reduction in thickness all along its structures $(10,54-57)$.

One of the most important findings in literature is related to MRI studies of septum pellucidum, 11 (92\%) describing an enlargement of this region in schizophrenia (10).

Akhtar et al conducted an MRI study of 66 subjects (33 with schizophrenia and 33 control test) and found that brain atrophy was present only in 13 patients with schizophrenia (39.4\%) and none of the control group. The presence of prominent cavum septum pellucidum was described in 10 cases of schizophrenia representing $30 \%$ and none in the control. Prominent Virchow Robin spaces were significantly associated with schizophrenia (30.3\%) as compared to the control group. Enlargement of ventricles was reported only in 4 cases $(12 \%)$ and $2(6 \%)$ of the control group (58). 


\section{First episode patient data}

MRI studies of first episode patients are quite comparable with those of chronic patients, especially in data regarding the reduction of the whole brain volume. Enlargement of lateral ventricles was described as positive in 15 studies out of 19 and is similar to the findings of chronic patients (59-61). Also, several researchers note the increase in volume of the left temporal horn of the lateral ventricles which is comparable with data gathered from chronic patients $(10,62,63)$.

Five out of 6 studies regarding medial temporal lobe structures report positive data for schizophrenic patients (10), in comparison with 5 out of 11 MRI studies that examined the whole temporal lobe volume $(45,64)$. When investigating the hippocampus and amygdala independently, 8 out of 10 studies report a diminished hippocampal volume and only 1 out of 5 studies report a decreased amygdala volume $(29,64,65)$.

Regarding the whole frontal lobe, 7 out of 10 MRI studies showed abnormalities, one of them noted asymmetry in the prefrontal cortex (9) and another one a diminished volume in the cingulate, while the other study reported negative findings (65).

For other brain regions, MRIs also gathered important data. From 4 studies of corpus callosum, 3 reported abnormalities; 7 out of 10 basal ganglia studies, and 3 out of 3 studies of cavum septum pellucidum reported abnormalities $(10,47,65-68)$.

\section{Chronic patient data}

The inceptive reports $(45,66,69)$ noted that there were no differences between the patients with first episode and the control group regarding the volume of ventricles. Previous studies revealed increased volume of lateral ventricles as the subject sample grew larger $(66,70)$.

In a 4-year study, DeLisi and coworkers (66) noted that there were no modifications in temporal lobe volume or in the amygdala-hippocampal complex.

\section{Conclusions}

Summarizing all of these studies regarding MRI imaging in patients with schizophrenia, the most frequent findings are enlargement of lateral ventricles, cortical atrophy, affecting mostly temporal and frontal lobes, and white matter abnormalities.

MRI findings thus demonstrate that brain abnormalities are present at first episode of the illness, and that the brain regions involved are the same brain regions observed in more chronic patients. There are some anomalies which progress over time, such as reduction in the volume of frontal and parietal lobes, superior temporal gyrus and lateral ventricles (10).

The changes in the volume of the basal ganglia seem to be related rather to the type and duration of neuroleptic treatment, whereas the volume of amygdala-hippocamp appears not to change over time.

It is still under debate whether the abnormalities described in this condition could be used as a biomarker for diagnosis. Hopefully, the new MRI technique with a higher resolution will offer new data regarding the brain anomalies in schizophrenia with a better understanding of the innermost pathogenic mechanism of this devastating disease, subsequently impacting the therapeutic interventions in these patients.

These data recommend MRI investigation as an important tool in the follow-up process of patients with schizophrenia.

In conclusion, regarding the continuous evolution of technology, MRI investigation may be considered a necessity and no longer a luxury in early schizophrenia diagnosis.

\section{Acknowledgements}

Not applicable.

\section{Funding}

The present work was supported partially by a grant from the Romanian National Authority for Scientific Research and Innovation CCCDI-UEFISCDI project number COFUND-ERANET NEURON SYNSCHIZ 6/2018.

\section{Availability of data and materials}

All information included in this Review is documented by relevant references.

\section{Authors' contributions}

FPI analyzed and collected data regarding the MRI findings. MCM analyzed and collected data regarding the MRI findings. MB was involved in revising the review critically for important intellectual content. AMC was involved in revising the review critically for important intellectual content. MM critically revised the manuscript. All authors read and approved the final manuscript for publication.

\section{Ethics approval and consent to participate}

Not applicable.

\section{Patient consent for publication}

Not applicable.

\section{Competing interests}

The authors declare that they have no competing interests.

\section{References}

1. van OS J and Kapur S: Schizophrenia. Lancet 374: 635-645, 2009.

2. Rofman ES: Kaplan and Sadock's synopsis of psychiatry. J Clin Psychiatry 11: 303, 2015.

3. McClellan J and Stock S; American Academy of Child and Adolescent Psychiatry (AACAP) Committee on Quality Issues (CQI): Practice parameter for the assessment and treatment of children and adolescents with schizophrenia. J Am Acad Child Adolesc Psychiatry 52: 976-990, 2013.

4. Davis J, Eyre H, Jacka FN, Dodd S, Dean O, McEwen S, Debnath M, McGrath J, Maes M, Amminger P, et al: A review of vulnerability and risks for schizophrenia: Beyond the two hit hypothesis. Neurosci Biobehav Rev 65: 185-194, 2016. 
5. Murray RM, Bhavsar V, Tripoli G and Howes O: 30 years on: How the neurodevelopmental hypothesis of schizophrenia morphed into the developmental risk factor model of psychosis. Schizophr Bull 43: 1190-1196, 2017.

6. Najjar S and Pearlman DM: Neuroinflammation and white matter pathology in schizophrenia: Systematic review. Schizophr Res 161: 102-112, 2015.

7. Bilder RM,Wu H, Bogerts B, Ashtari M, Robinson D, Woerner M, Lieberman JA and Degreef G: Cerebral volume asymmetries in schizophrenia and mood disorders: A quantitative magnetic resonance imaging study. Int J Psychophysiol 34: 197-205, 1999.

8. Andreasen NC, Flashman L, Flaum M, Arndt S, Swayze V II, O'Leary DS, Ehrhardt JC and Yuh WT: Regional brain abnormalities in schizophrenia measured with magnetic resonance imaging. JAMA 272: 1763-1769, 1994.

9. Bilder RM, Wu H, Bogerts B, Degreef G, Ashtari M, Alvir JM, Snyder PJ and Lieberman JA: Absence of regional hemispheric volume asymmetries in first-episode schizophrenia. Am J Psychiatry 151: 1437-1447, 1994.

10. Shenton ME, Dickey CC, Frumin M and McCarley RW: A review of MRI findings in schizophrenia. Schizophr Res 49: 1-52, 2001

11. Blackwood DH, Young AH, McQueen JK, Martin MJ, Roxborough HM, Muir WJ, St Clair DM and Kean DM: Magnetic resonance imaging in schizophrenia: Altered brain morphology associated with P300 abnormalities and eye tracking dysfunction. Biol Psychiatry 30: 753-769, 1991.

12. Colombo C, Abbruzzese M, Livian S, Scotti G, Locatelli M, Bonfanti A and Scarone S: Memory functions and temporal-limbic morphology in schizophrenia. Psychiatry Res 50: 45-56, 1993

13. Hoff AL, Riordan H, O'Donnell D, Stritzke P, Neale C, Boccio A, Anand AK and DeLisi LE: Anomalous lateral sulcus asymmetry and cognitive function in first-episode schizophrenia. Schizoph Bull 18: 257-272, 1992

14. Jernigan TL, Zisook S, Heaton RK, Moranville JT, Hesselink JR and Braff DL: Magnetic resonance imaging abnormalities in lenticular nuclei and cerebral cortex in schizophrenia. Arch Gen Psychiatry 48: 881-890, 1991

15. Lawrie SM, Whalley H, Kestelman JN, Abukmeil SS Byrne M, Hodges A, Rimmington JE, Best JJ, Owens DG and Johnstone EC: Magnetic resonance imaging of brain in people at high risk of developing schizophrenia. Lancet 353: 30-33, 1999.

16. Rossi A, Stratta P, D'Albenzio L, Tartaro A, Schiazza G, di Michele V, Bolino F and Casacchia M: Reduced temporal lobe areas in schizophrenia: Preliminary evidences from a controlled multiplanar magnetic resonance imaging study. Biol Psychiatry 27: 61-68, 1990

17. Rossi A, Stratta P, Mancini F, Gallucci M, Mattei P, Core L, di Michele V and Casacchia M: Magnetic resonance imaging findings of amygdala-anterior hippocampus shrinkage in male patients with schizophrenia. Psychiatry Res 52: 43-53, 1994.

18. Schwartz JM, Aylward E, Barta PE, Tune LE and Pearlson GD Sylvian fissure size in schizophrenia measured with the magnetic resonance imaging rating protocol of the Consortium to Establish a Registry for Alzheimer's disease. Am J Psychiatry 149: $1195-1198,1992$

19. Schwarzkopf SB, Olson SC, Coffman JA and Nasrallah HA: Third and lateral ventricular volumes in schizophrenia: Support for progressive enlargement of both structures. Psychopharmacol Bull 26: 385-391, 1990

20. Shenton ME, Kikinis R, McCarley RW, Metcalf D, Tieman J and Jolesz FA: Application of automated MRI volumetric measurement techniques to the ventricular system in schizophrenics and normal controls. Schizophr Res 5: 103-113, 1991.

21. Woodruff PW, Wright IC, Shuriquie N, Russouw H, Rushe T, Howard RJ, Graves M, Bullmore ET and Murray RM: Structural brain abnormalities in male schizophrenics reflect fronto-temporal dissociation. Psychol Med 27: 1257-1266, 1997.

22. Andreasen NC, Ehrhardt JC, Swayze VW II, Alliger RJ, Yuh WT, Cohen $\mathrm{G}$ and Ziebell S: Magnetic resonance imaging of the brain in schizophrenia. The pathophysiologic significance of structural abnormalities. Arch Gen Psychiatry 47: 35-44, 1990.

23. Roy PD, Zipursky RB, Saint-Cyr JA, Bury A, Langevin R and Seeman MV: Temporal horn enlargement is present in schizophrenia and bipolar disorder. Biol Psychiatry 44: 418-422, 1998.

24. Keshavan MS, Haas GL, Kahn CE, Aguilar E, Dick EL, Schooler NR, Sweeny JA and Pettegrew JW: Superior temporal gyrus and the course of early schizophrenia: Progressive, static, or reversible? J Psychiatr Res 32: 161-167, 1998.
25. Stratta P, Rossi A, Gallucci M, Amicarelli I, Passariello R and Casacchia M: Hemispheric asymmetries and schizophrenia: A preliminary magnetic resonance imaging study. Biol Psychiatry 25: 275-284, 1989

26. Cannon TD, van Erp TG, Huttunen M, Lönnqvist J, Salonen O, Valanne L, Poutanen VP, Standertskjöld-Nordenstam CG, Gur RE and Yan M: Regional gray matter, white matter, and cerebrospinal fluid distributions in schizophrenic patients, their siblings, and controls. Arch Gen Psychiatry 55: 1084-1091, 1998.

27. Gur RE, Cowell P, Turetsky BI, Gallacher F, Cannon T, Bilker W and Gur RC: A follow-up magnetic resonance imaging study of schizophrenia. Relationship of neuroanatomical changes to clinical and neurobehavioral measures. Arch Gen Psychiatry 55: 145-152, 1998.

28. Altshuler LL, Bartzokis G, Grieder T, Curran J and Mintz J: Amygdala enlargement in bipolar disorder and hippocampal reduction in schizophrenia: An MRI study demonstrating neuroanatomic specificity. Arch Gen Psychiatry 55: 663-664, 1998

29. Niemann K, Hammers A, Coenen VA, Thron A and Klosterkötter J: Evidence of a smaller left hippocampus and left temporal horn in both patients with first episode schizophrenia and normal control subjects. Psychiatry Res 99: 93-110, 2000.

30. Szeszko PR, Bilder RM, Lencz T, Pollack S, Alvir JM, Ashtari M, Wu H and Lieberman JA: Investigation of frontal lobe subregions in first-episode schizophrenia. Psychiatry Res 90: $1-15,1999$.

31. Buchanan RW, Vladar K, Barta PE and Pearlson GD: Structural evaluation of the prefrontal cortex in schizophrenia. Am J Psychiatry 155: 1049-1055, 1998.

32. Baaré WF, Hulshoff Pol HE, Hijman R, Mali WP, Viergever MA and Kahn RS: Volumetric analysis of frontal lobe regions in schizophrenia: Relation to cognitive function and symptomatology. Biol Psychiatry 45: 1597-1605, 1999.

33. Wible CG, Shenton ME, Fischer IA, Allard JE, Kikinis R, Jolesz FA, Iosifescu DV and McCarley RW: Parcellation of the human prefrontal cortex using MRI. Psychiatry Res 76: 29-40, 1997.

34. Nuechterlein KH and Dawson ME: Information processing and attentional functioning in the developmental course of schizophrenic disorders. Schizophr Bull 10: 160-203, 1984

35. Park S and Holzman PS: Schizophrenics show spatial working memory deficits. Arch Gen Psychiatry 49: 975-982, 1992.

36. Mesulam MM: Large-scale neurocognitive networks and distributed processing for attention, language, and memory. Ann Neurol 28: 597-613, 1990.

37. Frederikse M, Lu A, Aylward E, Barta P, Sharma T and Pearlson G: Sex differences in inferior parietal lobule volume in schizophrenia. Am J Psychiatry 157: 422-427, 2000.

38. Nopoulos P, Torres I, Flaum M, Andreasen NC, Ehrhardt JC and Yuh WT: Brain morphology in first-episode schizophrenia. Am J Psychiatry 152: 1721-1723, 1995.

39. Zipursky RB, Lim KO, Sullivan EV, Brown BW and Pfefferbaum A: Widespread cerebral gray matter volume deficits in schizophrenia. Arch Gen Psychiatry 49: 195-205, 1992.

40. Schlaepfer TE, Harris GJ, Tien AY, Peng LW, Lee S, Federman EB, Chase GA, Barta PE and Pearlson GD: Decreased regional cortical gray matter volume in schizophrenia. Am J Psychiatry 151: 842-848, 1994.

41. Levitt JJ, McCarley RW, Nestor PG, Nestor PG, Petrescu C, Donnino R, Hirayasu Y, Kikinis R, Jolesz FA and Shenton ME: Quantitative volumetric MRI study of the cerebellum and vermis in schizophrenia: Clinical and cognitive correlates. Am J Psychiatry 156: 1105-1107, 1999.

42. Goldstein JM, Goodman JM, Seidman LJ, Kennedy DN, Makris N, Lee H, Tourville J, Caviness VS Jr, Faraone SV and Tsuang MT: Cortical abnormalities in schizophrenia identified by structural magnetic resonance imaging. Arch Gen Psychiatry 56: 537-547, 1999.

43. Nopoulos PC, Ceilley JW, Gailis EA and Andreasen NC: An MRI study of cerebellar vermis morphology in patients with schizophrenia: Evidence in support of the cognitive dysmetria concept. Biol Psychiatry 46: 703-711, 1999.

44. Rossi A, Stratta P, Fabrizio M, de Cataldo S and Casacchia M Cerebellar vermal size in schizophrenia: A male effect. Biol Psychiatry 33: 354-357, 1993.

45. DeLisi LE, Hoff AL, Schwartz JE, Shields GW, Halthore SN, Gupta SM, Henn FA and Anand AK: Brain morphology in first-episode schizophrenic-like psychotic patients: A quantitative magnetic resonance imaging study. Biol Psychiatry 29: $159-175,1991$. 
46. Shihabuddin L, Buchsbaum MS, Hazlett EA, Haznedar MM Harvey PD, Newman A, Schnur DB, Spiegel-Cohen J, Wei T, Machac J, et al: Dorsal striatal size, shape, and metabolic rate in never-medicated and previously medicated schizophrenics performing a verbal learning task. Arch Gen Psychiatry 55: 235-243, 1998

47. Corson PW, Nopoulos P, Andreasen NC, Heckel D and Arndt S: Caudate size in first-episode neuroleptic-naive schizophrenic patients measured using an artificial neural network. Biol Psychiatry 46: 712-720, 1999.

48. Corey-Bloom J, Jernigan T, Archibald S, Harris MJ and Jeste DV: Quantitative magnetic resonance imaging of the brain in late-life schizophrenia. Am J Psychiatry 152: 447-449, 1995.

49. Symonds LL, Archibald SL, Grant I, Zisook S and Jernigan TL: Does an increase in sulcal or ventricular fluid predict where brain tissue is lost? J Neuroimaging 9: 201-209, 1999.

50. Staal WG, Hulshoff Pol HE, Schnack H, Van Der Schot AC and Kahn RS: Partial volume decrease of the thalamus in relatives of patients with schizophrenia. Am J Psychiatry 155: 1784-1786, 1998.

51. Gur RE, Maany V, Mozley PD, Swanson C, Bilker W and Gur RC: Subcortical MRI volumes in neuroleptic-naive and treated patients with schizophrenia. Am J Psychiatry 155: 1711-1717, 1998

52. Arciniegas D, Rojas DC, Teale P, Sheeder J, Sandberg E and Reite M: The thalamus and the schizophrenia phenotype: Failure to replicate reduced volume. Biol Psychiatry 45: 1329-1335, 1999.

53. Hazlett EA, Buchsbaum MS, Byne W, Wei TC, Spiegel-Cohen J, Geneve C, Kinderlehrer R, Haznedar MM, Shihabuddin L and Siever LJ: Three-dimensional analysis with MRI and PET of the size, shape, and function of the thalamus in the schizophrenia spectrum. Am J Psychiatry 156: 1190-1199, 1999.

54. Narr KL, Thompson PM, Sharma T, Moussai J, Cannestra AF and Toga AW: Mapping morphology of the corpus callosum in schizophrenia. Cereb Cortex 10: 40-49, 2000.

55. Downhill JE Jr, Buchsbaum MS, Wei T, Spiegel-Cohen J, Hazlett EA, Haznedar MM, Silverman J and Siever LJ: Shape and size of the corpus callosum in schizophrenia and schizotypal personality disorder. Schizophr Res 42: 193-208, 2000.

56. Chua SE, Sharma T, Takei N, Murray RM and Woodruff PWR: A magnetic resonance imaging study of corpus callosum size in familial schizophrenic subjects, their relatives, and normal controls. Schizophr Res 41: 397-403, 2000.

57. Meisenzahl EM, Frodl T, Greiner J, Leisinger G, Maag KP, Heiss D, Hahn K, Hegerl U and Moller HJ: Corpus callosum size in schizophrenia-a magnetic resonance imaging analysis. Eur Arch Psychiatry Clin Neurosci 249: 305-312, 1999.

58. Akhtar W, Naqvi H, Hussain S, Ali A and Ahmad N: Magnetic resonance imaging findings in patients with schizophrenia. J Coll Physicians Surg Pak 20: 167-170, 2010.

59. Barr WB, Ashtari M, Bilder RM, Degreef G and Lieberman JA Brain morphometric comparison of first-episode schizophrenia and temporal lobe epilepsy. Br J Psychiatry 170: 515-519, 1997.
60. James AC, Crow TJ, Renowden S, Wardell AM, Smith DM and Anslow P: Is the course of brain development in schizophrenia delayed? Evidence from onsets in adolescence. Schizophr Res 40: 1-10, 1999.

61. Whitworth AB, Honeder M, Kremser C, Kemmler G, Felber S, Hausmann A, Wanko C, Wechdorn H, Aichner F, Stuppaeck $\mathrm{CH}$, et al: Hippocampal volume reduction in male schizophrenic patients. Schizophr Res 31: 73-81, 1998.

62. Bogerts B, Ashtari M, Degreef G, Alvir JMJ, Bilder RM and Lieberman JA: Reduced temporal limbic structure volumes on magnetic resonance images in first episode schizophrenia. Psychiatry Res Neuroimaging 35: 1-13, 1990.

63. Degreef G, Ashtari M, Bogerts B, Bilder RM, Jody DN, Alvir JMJ and Lieberman JA: Volumes of ventricular system subdivisions measured from magnetic resonance images in first-episode schizophrenic patients. Arch Gen Psychiatry 49: 531-537, 1992.

64. Gur RE, Turetsky BI, Cowell PE, Finkelman C, Maany V, Grossman RI, Arnold SE, Bilker WB and Gur RC: Temporolimbic volume reductions in schizophrenia. Arch Gen Psychiatry 57: 769-775, 2000.

65. Ohnuma T, Kimura M, Takahashi T, Iwamoto N and Arai H: A magnetic resonance imaging study in first-episode disorganized-type patients with schizophrenia. Psychiatry Clin Neurosci 51: 9-15, 1997.

66. DeLisi LE, Sakuma M, Tew W, Kushner M, Hoff AL and Grimson R: Schizophrenia as a chronic active brain process: A study of progressive brain structural change subsequent to the onset of schizophrenia. Psychiatry Res 74: 129-140, 1997.

67. Kwon JS, Shenton ME, Hirayasu Y, Salisbury DF, Fischer IA, Dickey CC, Yurgelun-Todd D, Tohen M, Kikinis R, Jolesz FA, et al: MRI study of cavum septi pellucidi in schizophrenia, affective disorder, and schizotypal personality disorder. Am J Psychiatry 155: 509-515, 1998.

68. DeQuardo JR, Keshavan MS, Bookstein FL, Bagwell WW, Green WD, Sweeney JA, Haas GL, Tandon R, Schooler NR and Pettegrew JW: Landmark-based morphometric analysis of first-episode schizophrenia. Biol Psychiatry 45: 1321-1328, 1999.

69. DeLisi LE, Stritzke P, Riordan H, Holan V, Boccio A, Kushner M, McClelland J, Van Eyl O and Anand A: The timing of brain morphological changes in schizophrenia and their relationship to clinical outcome. Biol Psychiatry 31: 241-254, 1992.

70. DeLisi LE, Tew W, Xie S, Hoff AL, Sakuma M, Kushner M, Lee G, Shedlack K, Smith AM and Grimson R: A prospective follow-up study of brain morphology and cognition in first-episode schizophrenic patients: Preliminary findings. Biol Psychiatry 38: 349-360, 1995.

This work is licensed under a Creative Commons Attribution-NonCommercial-NoDerivatives 4.0 International (CC BY-NC-ND 4.0) License. 